\title{
Empirical Analysis of the Portuguese Governments Social Network
}

\author{
Nuno Moniz • Francisco Louçã · Márcia \\ Oliveira - Renato Soeiro
}

Received: date / Accepted: date

\begin{abstract}
The Portuguese governmental network comprising all the 776 ministers and junior ministers who were part of the 19 governments between the year 1976 and 2013 is presented and analysed. The data contains information on connections concerning business and other types of organizations and, to our knowledge, there is no such extensive research in previous literature. Upon the presentation of the data, a social network analysis considering the temporal dimension is performed at three levels of granularity: network-level, subnetwork-level (political groups) and node-level. A discussion based on the results is presented. We conclude that although it fits two of the four preconditions of a small-world model, the Portuguese governmental network is not a small-world network, although presenting an evolution pointing towards becoming one. Also, we use a resilience test to study the evolution of the robustness of the Portuguese governmental network, pinpointing the moment when a set of members became structurally important.
\end{abstract}

Keywords social network analysis · political network · members of government . portugal

Nuno Moniz gratefully acknowledges funding from FCT (Portuguese Foundation for Science and Technology) through a PhD grant (SFRH/BD/90180/2012). Renato Soeiro gratefully acknowledges funding from FCT through a PhD grant (SFRH/BD/88742/2012). Márcia Oliveira gratefully acknowledges funding from FCT through a PhD grant (SFRH/BD/81339/2011). Francisco Louçã acknowledges financial support by FCT as part of the strategic project PEstOE/EGE/UI0436/2014.

Nuno Moniz

LIAAD - INESC Tec, Oporto, Portugal

E-mail: nmmoniz@inescporto.pt

Francisco Louçã

UECE, ISEG (Lisbon School of Economics and Management), Lisbon University, Portugal

E-mail: flouc@iseg.utl.pt

Márcia Oliveira

LIAAD - INESC Tec, Oporto, Portugal

E-mail: mdbo@inescporto.pt

Renato Soeiro

LIAAD - INESC Tec, Oporto, Portugal

E-mail: rasoeiro@inescporto.pt 


\section{Introduction}

For decades, various fields of research have studied the development and dynamics of networks of power, be them economical, financial, political or otherwise. The connections established between actors provide evidence of their influence and reach, and the overview of such networks enables us to draw conclusions on how they were constructed and how they function and evolve. Thus, a social network approach seems suitable as it provides the tools to understand the roles individuals or groups play in the network and how they apply and are subjects of influence from other actors or groups.

On the subject of social networks related to institutional power, most of the studies have been focused on the corporate level, related to private or business sectors. Concerning political networks in general, interesting studies from various countries have been developed, but there are only few cases that venture into the social networks of governments.

The study of such networks has been mainly focused on the question of influence by businesses or corporations on governments. This means that a social network is built using the connections of people who are affiliated to these businesses or corporations and also to members of government. This provides important empirical evidence that enables the study of the relationship between the private and the public interest, allowing the analysis of the evolution of such networks. Also, the influence of political parties and their internal structure play a central role in the evolution of such networks, and should not be neglected. The relationship between members of these organizations and external entities are interlocked in a mediated dispute over political opinions and decisions. Therefore, this intercession is translated to the decisions of who is appointed to become a government member and in turn becomes historically relevant.

Additionally, these nominations are not exempted from the evaluation of the actors' ability to obtain and decide upon specific information. The process of obtaining information requires connections to external actors who provide it. In other words, to be "well connected" or to be able to establish the required connections. In fact, for some areas of governmental decision this does not present a big issue, but other issues arise regarding areas where the key external actors are also sources of power, such as economical or financial. The effect of the described mediation and centrality issues are clear when observing the nomination of people closely connected to the private sector. It provides a closer relation to the centers of information but it also has the effect of providing a central role to the actor nominated due to his/her connections.

The social and economical evolution of Portugal since the Carnation Revolution in April of 1974 provides the motivation and the context of this research. In the eve of this abrupt State change, the country was controlled by a small number of families, mainly concentrated in 7 major groups representing 300 companies. These were dominant in the basic sectors, in big industry of intensive capital, in the production of intermediate goods, in commercial banking, the insurance sector and maritime transportation [46]. The dictatorial state mainly used 5 instruments of economical control until 1974: forced concentration, protection of national capital from external competition, ensured high rate of exploitation, the colonial markets and the creation of companies and discretionary distribution of monopoly opportunities [30]. These groups suffered heavy losses upon the revolu- 
tion with the subsequent nationalizations. A decade later, in the $1980 \mathrm{~s}$, the first phase of privatizations was put into effect. Two other phases followed: one at the end of the 1990s, and another at the end of the first decade of this millennium. The evolution of the privatizations process ensured the reconstruction of most of the groups that controlled the Portuguese economy before 1974, with the emergence of some new groups. The reconstruction of these major economic powers was done under the direct influence of governmental decisions. The described framework of the course of contemporary political and economic history provides a considerable motivation to study the evolution dynamics of the Portuguese government social network. This is the theme for this work.

In this paper, we conduct a study of the Portuguese governmental network by resorting to Social Network Analysis (SNA) techniques. Since the governmental system is relational at its core, SNA is a suitable methodology for analysing the underlying network given its emphasis on the relationships among actors, rather than on the individual attributes that characterize them. We apply SNA aiming to achieve four distinct but intertwined goals: (i) describe the network topology and its centralization, (ii) uncover the implicit distribution of power, (iii) characterize the internal structure of the major political groups comprised in the network and compare them with the structure of the global network, and (iv) identify who are the most influential actors in the Portuguese governmental system. We support our analysis on network data corresponding to a time span of approximately four decades, starting at 1976 and ending at 2013, containing information on 776 appointed members of 19 Portuguese governments. This includes all members of the constitutional governments, established after the fall of the dictatorship that ruled Portugal from 1926 until 1974, excluding the democratic pre-constitutional provisional governments from 1974 until 1976.

In this study, we consider the temporal information and derive 19 cumulative networks (i.e., one for each government on our data), describing the evolution of the governmental network. Each network includes the relational information on all the members of previous governments and the connections established thereafter. These cumulative networks mirror the derived connections among members of several Portuguese governments over the course of approximately 37 years. Nodes in these networks represent members of the government (e.g., ministers and secretaries of state also referred to as junior ministers) and the links between them reflect relationships of different nature, such as formal, informal and/or organizational relationships. For instance, if two government members were in the government during the same time period, we assume they have a formal relationship. Otherwise, if they attended the same school, the relationship between them is assumed to be informal. In turn, if they held office in the same company/organization, they share an organizational relationship. Thus, the network is comprised of multidimensional relationships, which include belonging to the same government, the same school, political groups (e.g., political parties), and organizations or associations. Since some of these relationships overlap, the links are weighted by the number of relationships established between each pair of government members. This way we are able to capture the strength of the individuals' connections. The networks under analysis are, thus, aggregated, undirected and weighted social networks.

This paper is structured as follows: in Section 2 related research is described and discussed. The data used in this study is described in Section 3. In Section 4 
the experimental setting is laid out and results are presented in Section 5. We discuss their outcome in Section 6 and conclusions are presented in Section 7.

\section{Political Social Networks}

Given the scope of our study, there are three main approaches to the study of politics and power (financial, economical, etc.) which are of interest to our research: (i) the influence of politically-connected actors in corporations; (ii) the influence of interest groups and corporate-connected actors in governments; and (iii) the influence between actors within the scope of political parties or governments.

Agrawal and Knoeber [2] designed three tests in order to evaluate the importance of outside directors with background in politics and law on the boards of firms, for the United States of America. This evaluation resorted to the proportion of target variables (i.e., number of politically-connected directors in the board of a given firm) and economic indicators. Using a sample of manufacturing firms the authors discovered that (i) politically-connected directors are more frequent in firms with larger sales to government, exports and lobbying, and that in firms where costs of environmental regulation are higher, directors with background in law are more prevalent; that (ii) concerning electric utilities during the 1990s, when the effect of politics concerning regulation emerged, the number of politically-connected directors increased; and finally that (iii) given the data used, the authors found little evidence of political roles being played by women directors.

In the context of France, Bertrand et al. [7] studied whether the business elite modifies their corporate decisions in favor of politicians and their re-election. As documented by the authors, half of the CEOs in publicly-traded firms have a significant overlap with politicians concerning their professional and educational background. The results show that the hypothesis put forth by the authors is proven in several cases: the connections between CEOs and politicians have an impact on firms decisions such as job creation and destruction; in politically contested areas, the firms managed by connected CEOs create more jobs especially in election years; and, finally, that these "economic favours" are reciprocated with consistent evidence pointing to the privileged access to subsidy programs. These conclusions were mainly derived from the analysis of regression models. Niessen and Ruenzi [42] study the context of Germany and observe that politically-connected firms significantly outperform those that are not connected.

Faccio et al. [21] studied the likelihood of politically-connected firms obtaining a governmental bailout using a sample of 450 firms from 35 countries between 1997 and 2002. Results show that the politically-connected firms have a significantly higher likelihood of being bailed out than those that are not connected. This is disproportionally higher when the respective government receives financial assistance from the International Monetary Fund or the World Bank. Related to this issue, several studies (e.g. $[15,26,17])$ claim and support the idea that politically-connected firms have a preferential access to debt financing and higher leverage ratios than those non-connected. To investigate political connections in newly privatized firms Boubakri et al. [9] used a sample of 245 privatized firms of 41 countries (27 developing and 14 developed) between 1980 and 2002. Results show that 87 of these firms have a politician or ex-politician on their boards. The authors state that variables such as governmental residual ownership, political 
fractionalization and tenure, and judicial independence, are positively related to the likelihood of observing these political connections.

In Brazil, Bandeira-de-Mello and Marcon [33] studied the influence of corporations in politics. The authors used political contributions to proxy for firm connections, gathering a sample of 778 observations, claiming that affiliation to groups moderates the effect of the political connections concerning preferential lending. Furthermore, local business groups have a higher leverage than foreign groups when related to the use of political capability. Also, still related to Brazil, Claessens et al. [12] show that corporations which contribute significantly to political campaigns exhibit an increase in bank leverage. The authors conclude that political connections are an important channel in order to gain access to bank financing. This conclusion is also made by $\mathrm{Li}$ [27] concerning China, where the authors find that affiliation with the ruling Communist Party of China helps in obtaining loans from banks and other institutions.

As described, much work has been done concerning the effect of political connectivity on corporations and business, being mainly focused on the decisions and return results of the latter. These claims are essentially based on the use of regression and descriptive statistics. Nonetheless, some work focused on studying and drawing conclusions from the social network established by these corporategovernment connections has been conducted, such as the 1978 paper by Mokken and Stokman [35] concerning the case of the Netherlands.

As put forth by McClurg and Young [32], the task of understanding the processes underpinning politics, using a network approach, inevitably relies on a relational perspective. Also, due to this approach, the adopted view of power (explicit relation) is not in accordance with the standard approaches. Reasonable objections are raised related to the attempt of explaining phenomena using only relational information, such as self-determination or, in other words, the difference between causation and correlation. We believe this to be true, but to clarify, we do not attempt to use this data to propose a theory on the phenomenon, but rather to derive social networks and empirically study the dynamics of their evolution, presenting the conclusions and clues that they portray. Nevertheless, we believe that this relational approach, despite its limitations, provides a fundamental basis to understand political and social issues.

One of the main issues concerning endeavours such as ours is data availability, as mentioned by Siegel [47]. The data necessary to construct these networks is difficult to obtain, analyze and keep up-to-date. For example, in our case, the gathering of information on over 700 people, who were part of the 19 constitutional governments, had to be done manually and required a significant amount of time (approximately one year).

Concerning specific work regarding the use of social networks in politics, there have been important efforts to unveil the relationship that influence groups and voters establish with the government or politicians, but also the dynamics of the political parties. Concerning interest groups, Heaney [24] studies how they build reputation as key actors in policy-making processes in the case of health policy in the United States. Szwarcberg [50] provides a network analysis of clientelism in the context of Argentina, and Bello and Rolfe [6] oppose two social processes, selection and influence, in order to understand the forging of agreement in political discussion networks during campaigns. 
Parigi and Sartori [44] study the parties as organized networks of formal and informal relationships between individuals that reflects national cleavages. They analyze two major Italian parties in the 1970s to test their interpretation: the Christian Democrats and the Communists. To measure the formal and informal relationships amongst each party the authors use the cosponsoring of bills data from the lower chamber of the Italian Parliament between 1972 and 1977.

This literature review shows that no other research, to the best of our knowledge, matched the full scope of the data we are using. The most similar approach reports to the work by Gil Mendieta and Schmidt $[23,34]$. Their research motivated further work (see $[11,48,49]$ ) concerning Mexico's government network.

Our proposal is to provide a holistic approach to study the evolution of the social network of members of government given a significant time frame, including not only their political connections, but also their social, educational, corporate and otherwise professional connections. Therefore, our approach intends to synthesize the referred three approaches, providing a framework that enables each of the approaches to be applied to some extent.

\section{Data}

During the course of one year, an exhaustive research was carried out ${ }^{1}$ in order to gather data on the connections of all members of government in Portugal since $1976^{2}$ [36]. This database served as the basis for an unique study [30] in Portugal, which is built on previous work [14] concerning the political history of the accumulation of wealth during one century (from 1910 until 2010). This database includes information on 776 persons, ministers and secretaries of state (junior ministers) in the 19 governments until July of 2013, who occupied 1281 positions.

Based on public information, this database allows the identification and registry of the careers and direct corporate connections of each government member. It also contains information on their education and professional background, as well as business and political history. Groups of interest and clubs, or any other forms of links in associations, open or private, secret or semi-secret, were not included, due to the lack of reliable and reasonably related information. In order to enable a thorough analysis, some links where highlighted, such as the ones linking to big economic and financial groups, to companies connected to public-private partnerships, and to the top firms in the Portuguese stock market index (PSI20).

Regarding political affiliation, our database contains 7 political groups. Besides 5 parties, the Socialist Party (PS), the Social-Democratic Party (PSD), the Democratic and Social Centre - Popular Party (CDS/PP or CDS), the Popular Monarchic Party (PPM) and the Democratic Renewal Party (PRD), we include a group of government members of the Democratic Alliance (AD), and those who presented themselves as Independents. AD was a centre-right coalition between 1980 and 1983 which assumed government for that period, mainly including members of the political parties PSD, CDS/PP and PPM. Some members did not have any political affiliation to any of the parties but were part of the coalition, and therefore we assumed that they would form a separate group for analysis. Table 1 shows the number of government members for each political group.

1 This research was carried out by Nuno Moniz and Adriano Campos.

2 This was the year of the first constitutional government after the Carnation Revolution. 
Table 1 Total number of government members and corresponding number of corporateconnected members per political group.

\begin{tabular}{|l|l|l|}
\hline Political Groups & Gov. Members & Corporate-Connected \\
\hline PS & 295 & $140(47,5 \%)$ \\
PSD & 296 & $189(63,9 \%)$ \\
CDS/PP & 54 & $34(63 \%)$ \\
PPM & 3 & $1(33,3 \%)$ \\
PRD & 1 & $1(100 \%)$ \\
AD & 46 & $16(34,8 \%)$ \\
Indep. & 81 & $34(42 \%)$ \\
\hline
\end{tabular}

Our database comprises 6670 entries of relational data (person-organization) on the 776 members of Government since 1974. Of this total, there were 78 (10\%) members for whom no relational information was found, besides their presence in a given government. Concerning the members who have corporate-connections, the total is $415(53,5 \%)$, and there are 283 members $(36,5 \%)$ for whom we did not find any connection of that sort. Some members in our database were part of governments led by different political groups. In that case, our criteria as to political affiliation was set according to the party leading the last government in which the member participated. Additionally, there were cases where public information portraying a posterior change of affiliation was found, evidence that we took into consideration. Concerning the number of positions (1281 in total) played in all governments we observe that those which contain corporate-connections are the majority, with 719 positions (56\%).

\subsection{Professional Background}

In this section we present the results concerning the professional background of the members of government in our database. After examination of the database we defined a list of possibilities as to the professional positions before assuming a government position, as follows:

1. Alderman/Municipal Council Member

2. Member of Parliament

3. Board of Directors

4. University Position

5. Board of Directors and University Position

6. Board of Directors and Alderman/Municipal Council Member

7. Board of Directors and Member of Parliament

8. University Position and Member of Parliament

9. Public Employee

10. Private Employee

11. International Organization

12. Member of Parliament and Alderman/Municipal Council Member

13. Member of Parliament and Private Employee

Based on this list, Table 2 depicts the overall professional background of the members of government in our database before assuming government positions, except for those 78 for whom no information was found and those 139 members for whom the first information available is the presence in the government. 
Table 2 Professional background of 559 government members before assuming that position. The numbered list in the rows is referred to the list of possibilities previously enumerated.

\begin{tabular}{|l|lllllll|l|}
\hline Background & PS & PSD & CDS/PP & PPM & PRD & AD & Indep. & Total \\
\hline $\mathbf{1}$ & 12 & 6 & 0 & 0 & 0 & 0 & 0 & 18 \\
$\mathbf{2}$ & 49 & 57 & 15 & 2 & 0 & 1 & 1 & 125 \\
$\mathbf{3}$ & 29 & 54 & 6 & 0 & 1 & 4 & 6 & 100 \\
$\mathbf{4}$ & 52 & 34 & 8 & 0 & 0 & 5 & 12 & 111 \\
$\mathbf{5}$ & 2 & 1 & 0 & 0 & 0 & 0 & 1 & 4 \\
$\mathbf{6}$ & 1 & 1 & 0 & 0 & 0 & 0 & 0 & 2 \\
$\mathbf{7}$ & 2 & 8 & 2 & 0 & 0 & 0 & 0 & 12 \\
$\mathbf{8}$ & 4 & 5 & 4 & 0 & 0 & 0 & 0 & 13 \\
$\mathbf{9}$ & 49 & 35 & 4 & 0 & 0 & 4 & 12 & 104 \\
$\mathbf{1 0}$ & 13 & 12 & 8 & 1 & 0 & 0 & 6 & 40 \\
$\mathbf{1 1}$ & 5 & 6 & 1 & 0 & 0 & 1 & 0 & 13 \\
$\mathbf{1 2}$ & 4 & 4 & 0 & 0 & 0 & 0 & 0 & 8 \\
$\mathbf{1 3}$ & 1 & 5 & 3 & 0 & 0 & 0 & 0 & 9 \\
\hline
\end{tabular}

The table allows an analysis of the dominant profile for government members of each political group. Focusing on the groups that have a major global weight, it is possible to observe that PS and PSD (the two major political parties in Portugal today) are comparable. Their preference is for people who, before assuming government positions, were members of Parliament, members of Business Boards of Directors, University faculty, and public employees and officials. However, there is a distinctive difference between these two groups concerning backgrounds in Business Boards of Directors and University faculty: it is clear that in the case of PSD, there is a preference for the former, while in the case of PS the preference lies in the latter. Overall, data shows that PSD has a preference for members with a background in private sector, whilst PS shows a preference for public sector background. Nevertheless, both of them favor elected party members. Additionally, the background profile of the independent members in governments show that the majority comes from University faculty or from positions in the public sector.

Generally, the data shows that the members of constitutional governments after the Carnation Revolution (1974) formed a renewed political elite, mainly recruited from the State and, in a lesser extent, from businesses, with Public Sector, University and Parliament formatted professional experience.

\subsection{Corporate Connections}

In order to properly analyze corporate connections it is necessary to capture different dynamics describing the data: before and after being in government, economical sectors and the influence of the corporate elite (here, we include the major economical groups in Portugal and also the groups indexed in the stock-market).

To study the influence of economical sectors in recruitment we established a list of connections to each of these sectors per political group (Tables 3 and 4).

1. Banks and Finance and Monetary Intermediation except Insurance

2. Insurance, Pension Funds and Complementary Activities

3. Manufacturing except Construction

4. Power, Oil and Natural Resources

5. Real Estate and Construction

6. Communications 


\section{Media}

Table 3 Number of members of government connected to economic sectors and an indication of cases in which the members have connections to three or more of these sectors.

\begin{tabular}{|l|lllllll|l|}
\hline Econ. Sector & PS & PSD & CDS /PP & PPM & PRD & AD & Indep. & Total \\
\hline $\mathbf{1}$ & 57 & 83 & 16 & 0 & 0 & 7 & 12 & 175 \\
$\mathbf{2}$ & 18 & 19 & 5 & 1 & 0 & 2 & 6 & 55 \\
$\mathbf{3}$ & 27 & 44 & 8 & 1 & 1 & 1 & 11 & 93 \\
$\mathbf{4}$ & 41 & 42 & 7 & 0 & 1 & 4 & 5 & 100 \\
$\mathbf{5}$ & 42 & 37 & 6 & 0 & 0 & 6 & 4 & 95 \\
$\mathbf{6}$ & 24 & 24 & 2 & 0 & 0 & 1 & 3 & 54 \\
$\mathbf{7}$ & 14 & 18 & 2 & 0 & 0 & 4 & 3 & 41 \\
\hline Three + & 30 & 40 & 6 & 0 & 0 & 4 & 4 & 84 \\
\hline
\end{tabular}

It is possible to observe that PSD is the most connected to all economical sectors, with an exception concerning Real Estate and Construction (PS). The data clearly shows that the financial sector is the most influential. Nonetheless, a high number of connections to industry (manufacturing, power, oil, natural resources and construction) should be noted, representing a third of members of government in our database. Additionally, by signaling those who possess connections to three or more sectors, we again conclude that PSD presents the highest incidence.

We have found a considerable number of connections to companies indexed in the Portuguese Stock Market top list (PSI20), with data demonstrating that around $20 \%$ of members of government in our database are connected to such companies. The following table (Table 4) analyzes three distinct situations: (i) members connected to PSI20 indexed companies before becoming members of government, (ii) members connected before and after, and (iii) members connected only after being in government.

Table 4 Number of situations in which members of each political party have connections to the Portuguese Stock Market top index firms before assuming a position in government, after, and both.

\begin{tabular}{|l|lllllll|l|}
\hline PSI20 & PS & PSD & CDS/PP & PPM & PRD & AD & Indep. & Total \\
\hline Before & 11 & 27 & 6 & 0 & 0 & 0 & 0 & 44 \\
After & 43 & 54 & 8 & 0 & 0 & 5 & 8 & 118 \\
Both & 7 & 22 & 4 & 0 & 0 & 0 & 0 & 33 \\
\hline
\end{tabular}

Results show what could be called "the promotion effect": the ascending economic and social mobility of members of government after completing their term, contemplating $60 \%$ of the cases. Furthermore, it shows evidence of recruitment of members with experience in these companies who, after completing their term, return to companies in the Portuguese Index. As the data show, this situation is more frequent in members affiliated with PSD.

Finally, we observed connections to the major Portuguese economic groups, focusing on 12 of these groups ${ }^{3}$. We have found that 160 members $(21 \%)$ in our

\footnotetext{
3 Grupo Mello, Grupo Champalimaud, BES, BCP, Santander, Mota-Engil, PT, BPI, CGD, SONAE, Jerónimo Martins, Américo Amorim
} 
database are connected to at least one of these major economic groups. The following table illustrates this information.

Table 5 Members of government in our database with one or more connections to a group of the Portuguese major economical groups.

\begin{tabular}{|l|lllllll|l|}
\hline Big Groups & PS & PSD & CDS/PP & PPM & PRD & AD & Indep. & Total \\
\hline Connected & 55 & 74 & 13 & 0 & 1 & 3 & 14 & 160 \\
Two + & 12 & 12 & 3 & 0 & 0 & 0 & 2 & 29 \\
\hline
\end{tabular}

The table confirms the previous conclusions regarding the political groups preference with regard to the profile of members of government, with PSD contemplating almost half of the cases $(46 \%)$.

\section{Experimental Setting}

The methodology for analyzing the governmental network and its evolution is divided into four major steps, for which different SNA measures and techniques are applied. This methodology is applied to each of the 19 cumulative networks (i.e., one per government), which encompasses data on each of the governments and those that came before it. In other words, we use a landmark window model to model the dynamic governmental network. The two first steps of our analysis are focused on the macroscopic properties of the dynamic network, aiming to empirically derive its defining characteristics. These properties mirror the collective social structure of the network and arise as a result of the social interplay among the nodes over time. In the two final steps we refine our analysis by focusing on microscopic elements, in order to grasp insight and make sense of the contribution of low-level structures to the topology of the dynamic network. These elements are (i) the natural communities defined by the affiliation to a given political party, and the (ii) nodes themselves. By changing the level of analysis from the network to the communities and, then, to the nodes, we expect to achieve a deeper understanding of the Portuguese governmental network and its evolution.

\subsection{General configuration}

The first step aims at understanding the general configuration of the cumulative networks and derive some information from their overall structure, in order to obtain empirical evidence regarding the emergence of power and the level of cohesion among government members. For this purpose, we compute the network centralization index and the small-world proximity ratio, as well as classical network-level measures, such as the density, the diameter, the average degree, the global clustering coefficient and the average geodesic distance.

The network centralization index $[49,22]$ measures the degree to which a network is centralized in a small set of actors, with respect to a given centrality measure. We chose the power centrality index proposed by Gil and Schmidt [23] to compute the network centralization. The reasons behind the choice of this measure are: (i) it was specifically devised to measure the power of actors in political 
networks [23]; and (ii) it takes into consideration not only the number of direct connections of a given focal actor but also the influence of all the other actors that can be accessed through paths in the network by the focal actor. Therefore, we consider that the power centrality index better captures the notion of influence and power. This index relates the concepts of degree and closeness of a given node, as it considers not only the direct connections of this focal actor but also its non-adjacent connections to all the nodes that can be reached by paths in its maximum-order neighborhood. These non-adjacent connections are proportionally weighted according to their distance from the focal node. Thus, higher weights are assigned to nodes that are closer to the focal node and smaller weights to nodes that are farther apart. In theory, the higher the centralization index of the governmental network, the higher the concentration of power in a few number of actors, and the higher the risk of network disconnection due to its strong dependence on a few central nodes. However, the theoretical relationship between the network centralization and the risk of disconnection is not always empirically observed, since it is highly dependent on the idiosyncratic properties of the network.

Besides centralization, we also considered relevant to investigate the degree of small-worldliness of the governmental network. The small-world phenomenon, i.e., the idea that most of individuals in the network are connected by very short chains of acquaintances, has been observed not only in social networks but also on biological and technological networks $[1,37,16,5]$. Research has shown that smallworld networks are neither completely random nor ordered [53,52]. Instead, they lie somewhere between a regular lattice and a random graph [20], thus displaying properties of both extreme models: a high local clustering coefficient, typical of regular lattices, and a remarkably small average path length, typical of random graphs. The result is a network where short-range connections coexist with longrange connections. The small-worldliness of a network can be summarized in a scalar quantitative measurement, the small-world proximity ratio $\mu$ [51], which is computed as follows:

$$
\mu=\frac{\gamma}{\lambda}, \quad \text { where } \quad \gamma=\frac{C}{L} \quad \text { and } \quad \lambda=\frac{C_{\text {random }}}{L_{\text {random }}}
$$

where $\gamma$ is the ratio of the clustering coefficient to the average path length of the governmental network and, analogously, $\lambda$ is the ratio of the same measures obtained in a random network with the same number of nodes and the same average degree of the governmental network. Note that the values of $\lambda$ are averaged for $r$ random networks (in our case, $r=1000$ ). The proximity ratio $\mu$ is equal to one in random graphs, and is substantially greater than one $(\mu>>1)$ in networks with a small-world topology.

Even though the Portuguese governmental cumulative networks are weighted, for the sake of simplicity, comparability and interpretability, we compute the unweighted versions of the above presented network-level measures. Nevertheless, we explore the richness of the information provided by the links weights in the following steps of our methodology. 


\subsection{Distribution of power}

The second step of our analysis focuses on the study of the distribution of power in the networks, which is carried out by analyzing the weighted degree distribution (i.e., the distribution of the sums of links weights for each node). Power is a multifaceted construct, which can be captured by several SNA centrality measures. In this step, we attempt to capture only one facet of power, namely, the intensity of a politician's influence on his personal sphere. This is measured by the weighted degree of a node, which is basically the strength of a politician's direct connections. To better understand the relevance of analyzing the weighted degree distribution, we will draw on the findings from a significant body of research that studied the (unweighted) degree distribution of real networks.

The degree distribution $p(k)$ is a relevant property of networks and indicates, for each possible degree value $k$, the fraction of nodes in the network having this degree value. Numerous studies found that the degree distribution of several realworld networks (e.g., citation networks, scientific collaboration networks, phonecall networks, email networks, the World Wide Web) follows a power-law $p_{k} \sim k^{-\alpha}$ in its tail, with the scaling exponent typically lying in the range $2 \leq \alpha \leq 3[39,19,3$, 41,13 . This property means that such networks are characterized by the presence of many low degree nodes and a few nodes with extremely high degrees, usually termed hubs. A well-known explanation for the emergence of such heavy-tailed degree distributions is the so-called cumulative advantage process [45]. This richget-richer behavior manifests when the amount one gets of something depends on the amount one already has. The same logic can be applied to the weighted degree distribution. Similarly to the unweighted distribution, it is not uncommon to find real networks in which the tail of the weighted degree distribution fits a powerlaw $[29,28]$. This property manifests itself in networks where a small set of nodes connected by very strong ties coexist with a very large set of nodes exhibiting a much weaker relationship with their direct connections.

In the context of governmental networks, we hypothesize that power, as defined, is cumulative and concentrated in the hands of an elite and, therefore, is not evenly distributed. We assess the plausibility of this hypothesis by fitting a powerlaw distribution to the observed weighted degree distribution and by performing a Kolgomorov-Smirnov goodness-of-fit test, via a bootstrapping procedure, according to the guidelines of Clauset et al. [13]. If the resulting $p$-value is large, there is enough statistical evidence to conclude that the weighted degree displays a nontrivial power-law behavior. Otherwise, if the $p$-value is small, we conclude that the power-law model does not offer a plausible fit to the observed weighted degree and another distribution might be more appropriate to characterize it.

\subsection{Political groups}

The third step is targeted at the analysis of the natural political communities comprised in the networks. The starting point of the analysis is the extraction of the vertex-induced subgraphs associated with each Portuguese political party (e.g., PS, PSD). Then, the structure of each one of these induced subgraphs is characterized based on the same set of network-level measures used to describe the global network (see Section 4.1). The goal is to assess the degree of structural 
similarity between communities over time, as well as to infer on their similarity (or dissimilarity) with the associated cumulative networks.

\subsection{Influential actors}

The final step of our study focuses on the nodes. The goal is to identify the set of most influential government members, as measured by distinct centrality measures, and its influence on the overall network through a resilience test. This analysis is performed over time, to infer on the stability of these sets of influential nodes.

Centrality measures the importance of social actors by analyzing their positions within the structure of a social network. The notion of important actor is multidimensional since it can be associated with, for instance, reachability, connectivity, accessibility or control of resources (e.g., information flows) in the network. Thus, several centrality measures have been proposed to capture one or more of these dimensions. Examples of classical measures include the degree centrality, the betweenness centrality, the closeness centrality and the eigenvector centrality. The first three were proposed by Freeman [22] and were originally developed for unweighted networks. Newman [38], Brandes [10], Barrat et al. [4] and Opsahl et al. [43] came up with extensions to weighted networks. The fourth mentioned measure, the eigenvector centrality, was proposed by Bonacich [8] and has its foundations on spectral graph theory. For the dynamic network analysis we resort to the weighted versions of these centrality measures. We use the weighted closeness measure proposed by Newman [38], and the generalized betweenness measure proposed by Brandes [10]. To compute the eigenvector centrality scores for each node in the weighted network, we consider the weighted adjacency matrix instead of the unweighted one [40]. Besides these classical measures, we also compute the power centrality index [23], which was specifically devised for measuring the power of politicians in political networks. According to this index, the power of a node $i$ is defined not only by its direct connections but also by the nodes that can be reached from these. The power centrality index is computed as follows:

$$
I_{i}=\frac{1}{n-1}\left\{n_{1}(i)+\frac{1}{2} n_{2}(i)+\frac{1}{3} n_{3}(i)+\ldots+\frac{1}{d} n_{d}(i)\right\}, \quad 0<I_{i}<1
$$

where $n$ is the number of nodes in the network, $n_{1}(i)$ denotes the number of direct connections of node $i$ (equivalent to the degree centrality of node $i$ ) and $n_{d}(i)$ is the number of nodes at distance $d$ from node $i$. In this study, we consider $d$ to be the maximum-order neighborhood of a given node, in order to capture the full extent of its influence.

After computing these centrality measures, we list the names of the government members appearing in the top 10 ranking of each one of these measures. We then identify the overlap of names in the generated rankings. Those government members occurring in at least half of the rankings are considered to be the most influential and powerful nodes in the network.

Regarding the resilience tests, these are carried out in each one of the cumulative networks aiming to understand the evolution of the network in terms of robustness and the role of the most influential governments members. The results 
of these tests should point to a more precise evaluation of the appearance and de facto influence of these highly influential nodes concerning the global network.

\section{Portuguese Government Members Network}

In this section the results of the social network analysis are presented. Following the experimental design introduced before, this analysis is divided into four steps that explore increasing levels of network granularity: (i) general configuration of the networks, (ii) distribution of power, (iii) analysis of the political groups subnetworks, and (iv) identification of influential members. The methodology is applied to the evolving Portuguese governmental network, comprising the nodes and links observed from 1976 until 2013. In order to allow for the analysis of the dynamic network, we resort to the landmark window model to construct the networks at each time point. This model is initialized with the nodes and links from the first available government (i.e., the government from 1976) and then it grows the window by cumulatively aggregating all the nodes and links seen so far after the landmark. Since governments are natural divisions of the network into snapshots, there will be 19 snapshots, each associated with a given government. The dynamic governmental network is thus modelled as a temporally ordered sequence of 19 network snapshots $\left\{G_{1}, G_{2}, \ldots, G_{19}\right\}$, where $G_{i}=\left(V_{i}, E_{i}, W_{i}\right)$ represents a static cumulative snapshot of the network depicting all the nodes and links observed up to the $i$-th government. The landmark window model successively aggregates these static snapshots into a unique network and, thus, we will have $19 \mathrm{cumu}-$ lative networks, spanning the time period starting at 1976 and ending at 2013. These cumulative networks are derived based on this approach and analysed in the following subsections.

\subsection{General Configuration}

Here we present the network-level measures obtained for the evolving Portuguese governmental network, which are given in Figures 1 and 2. These measures allow us to derive information about the topology of the dynamic network and its structural configuration. We remind that the dynamic network under analysis is aggregated, undirected and weighted. The complete dynamic network comprises information on 776 members of all governments in our data set, connected by 72575 links. Each network snapshot is a temporal representation of the Portuguese governmental network up to the $i$-th government $(i=1, \ldots, 19)$.

\subsubsection{Network Centralization}

The network centrality index of the most recent Portuguese governmental network is high when compared to other political networks, such as the political network of Mexico [49]. This finding reveals the presence of a core set of actors, which occupy a central position in the network structure and, thus, exert much influence on the overall network. We note that the presence of this core set of actors, as suggested by the network centrality index, is steady since approximately the 10th Government (1985-1987). We also observe some fluctuations in network centralization between 

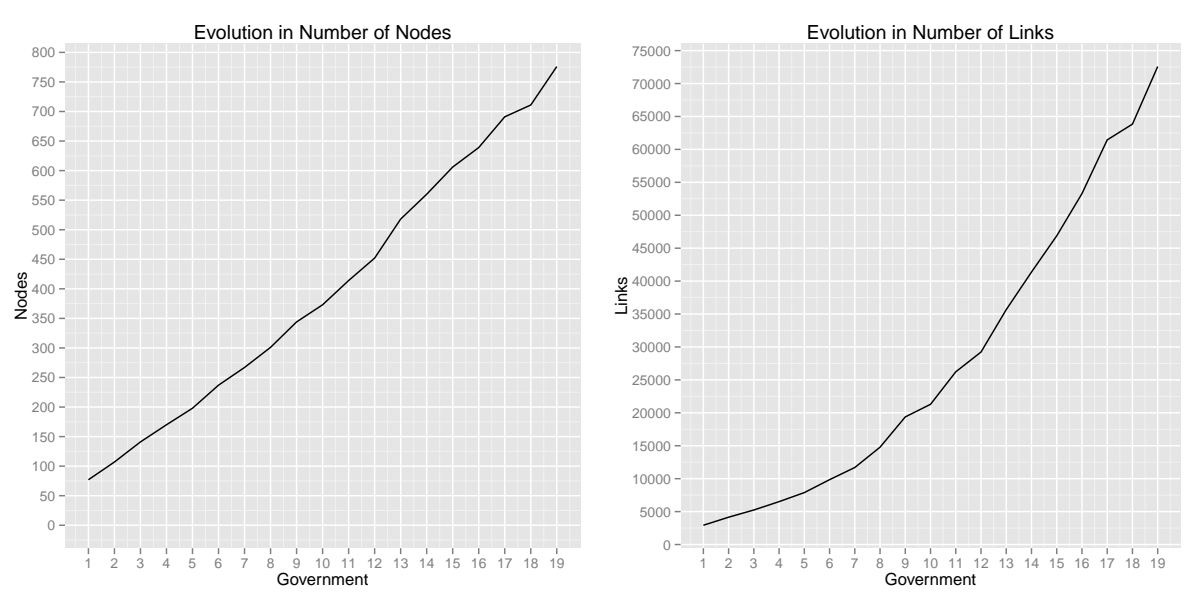

Fig. 1 Evolution in number of nodes and links between nodes throughout the 19 Portuguese governments.
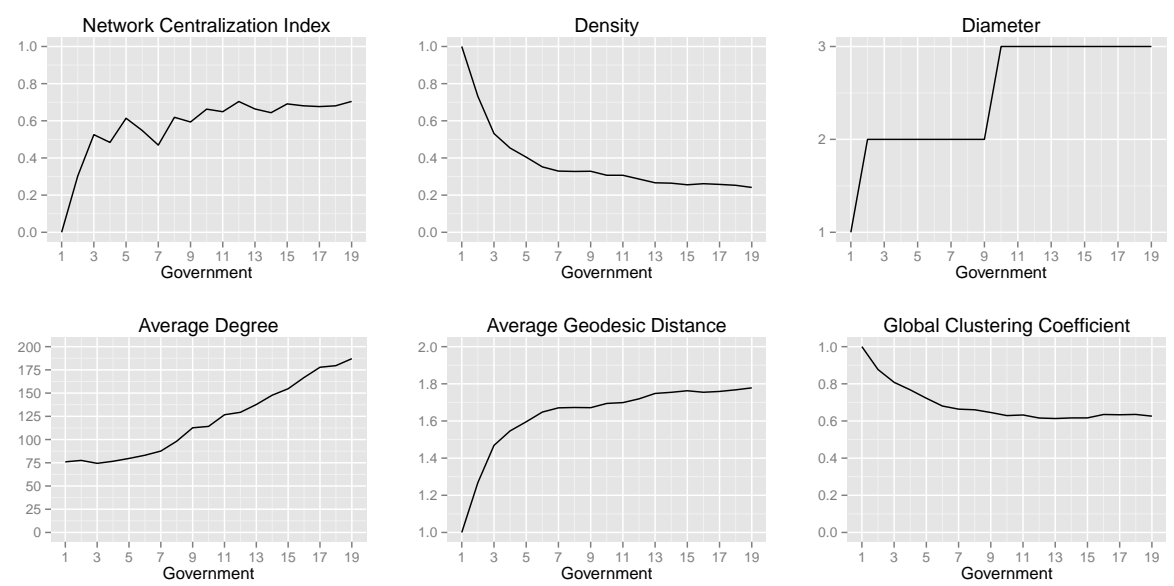

Fig. 2 Evolution of the network centralization index, density, diameter, average degree, average geodesic distance and global clustering coefficient in the 19 states of the evolving Portuguese governmental network.

the 3rd and the 9th governments, which may be explained, on one hand, by political instability in the first years after the change in the regime and, on the other hand, by short term governments comprised of different political parties.

\subsubsection{Degree}

The average degree of the most recent state of the network indicates that, on average, each member of the government is connected to 189 other members. According to Dunbar's research [18], an individual is cognitively able to comfortably maintain a maximum number of 150 stable social relationships, a threshold exceeded since the 15th government. Also, these networks only account for the connections within 
the Portuguese governmental network, and thus may underestimate the true number of social connections, as it does not account for those connections outside of this scope. Given this, our results suggest that the government members in our network potentially maintain, on average, a significantly large number of stable social relationships, which can be explained by the social context in which these actors are embedded.

\subsubsection{Connectivity}

The general level of connectivity among actors, as measured by density, is equivalent to other political networks [49]. Nonetheless, it is possible to observe that after a sharp decrease of the general level of connectivity in the first governments due to the debut of many different actors, the density score has decreased very slowly but steadily since the 6th Government (1980-1981). This suggests that the number of connections established between members of the government increases at a slower rate than the number of new government members.

\subsubsection{Clusters}

The network is also globally clustered as indicated by the large clustering coefficient. This value signals the presence of cohesive groups of actors characterized by a high density of links among them in the governmental network. Social networks typically display high values of this coefficient due to their transitivity, i.e., the likelihood of finding actors whose direct neighbors are also connected to each other. This result was expected given our definition of connection: we consider that all government members are tied to each other if they are members of the same government. As a consequence, the number of triangles in the network is expected to be large. The size of the largest clique in the most recent state of the governmental network corroborates this claim. The largest clique contains 246 individuals, which is an extremely high value when compared to other social networks. Given that a clique is a complete subgraph, where all possible links are present, our result indicates the existence of a tightly-knit group of 246 government members who are all connected to each other. The presence of this large clique in the most recent state of the dynamic network partly explains the high values obtained for the clustering coefficient and reveals a high level of redundancy in the relationships among government members. Additionally, we observe that this coefficient has remained steady since the 10th Government with an approximate value of 0.6.

\subsubsection{Reachability}

The strong cliqueness of the governmental network may also explain the small values of both the average geodesic distance and the diameter. These measures indicate that, on average, approximately two connections are needed to reach anyone in the network and, in the worst case, this number of connections increases to three. Regarding the former, we note its inverse relation with the density of the cumulative networks through time. This inverse relationship makes sense since the lower the density, the lower the number of links among nodes, and the longer 
the average shortest paths that connect them, which reflects in a higher average geodesic distance. As for the latter, the diameter increased to three with the addition of the 10th government in the dynamic network.

\subsubsection{Small-Worldliness}

The high value of global clustering coefficient and the low value of average path length seem to suggest that the governmental network is a 'small-world'. In order to evaluate the validity of this hypothesis, we computed the small-world proximity ratio and obtained $\mu=2.56$ for the most recent state of the governmental network. The evolution of the small-world proximity ratio is depicted in Figure 3.

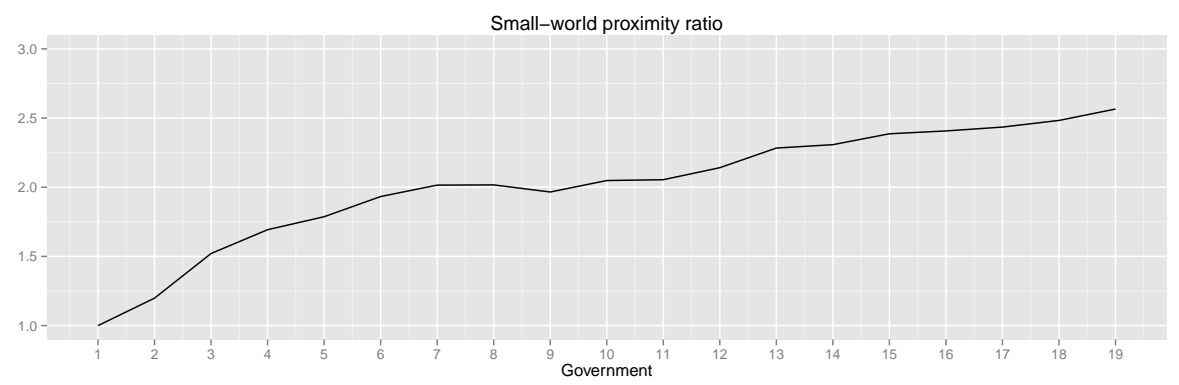

Fig. 3 Evolution of the small-world proximity ratio $\mu$ for the Portuguese governmental dynamic network.

According to the literature, in order to prove this hypothesis the value should be substantially greater than one $(\mu>>1)$. Although the Portuguese governmental network displays the two main properties of a small-world network, namely, a high local clustering $(C=0.62)$ and an extremely small average geodesic distance $(L=1.77)$ when compared with the network size $(m=73385)$, the $\mu$ value obtained for this network suggests that this pattern is not strong. This is explained by the high centralization and density of the governmental network. According to Watts [52], four preconditions must be met in order for a network to be considered a small-world. However, our network does not satisfy two of them, because it is neither sparse (each node has a large number of connections relative to the total number of nodes in the network), nor decentralized (it comprises a set of highly central actors, with extremely high degrees). Additionally, we observe that the small-world proximity ratio $\mu$, with one single exception (the 9th Government) has been increasing steadily. This tendency may point to the fact that the Portuguese Government network could become a small-world network in the future.

\subsection{Distribution of Power}

In the second step of the network-level analysis, we study the distribution of power as measured by the weighted degree. With this purpose, we performed the Kolmogorov-Smirnov goodness-of-fit test, via a bootstrapping procedure, to 
each one of the 19 states of the dynamic governmental network, by following the guidelines of Clauset et al. [13], and obtained a $p$-value $=0.6$ for the most recent state of the network. Figure 4 shows the Cumulative Distribution Function (CDF) of the weighted degree tail distribution for the most recent governmental network, along with the maximum-likelihood power-law fit for the Portuguese governmental network. The parameters of the power-law distribution were estimated using the Maximum Likelihood Estimation (MLE). Additionaly, the evolution of $k_{m i n}^{w}, \alpha$ and $p$-value is presented in Figure 5.

CDF of the Weighted Degree Distribution

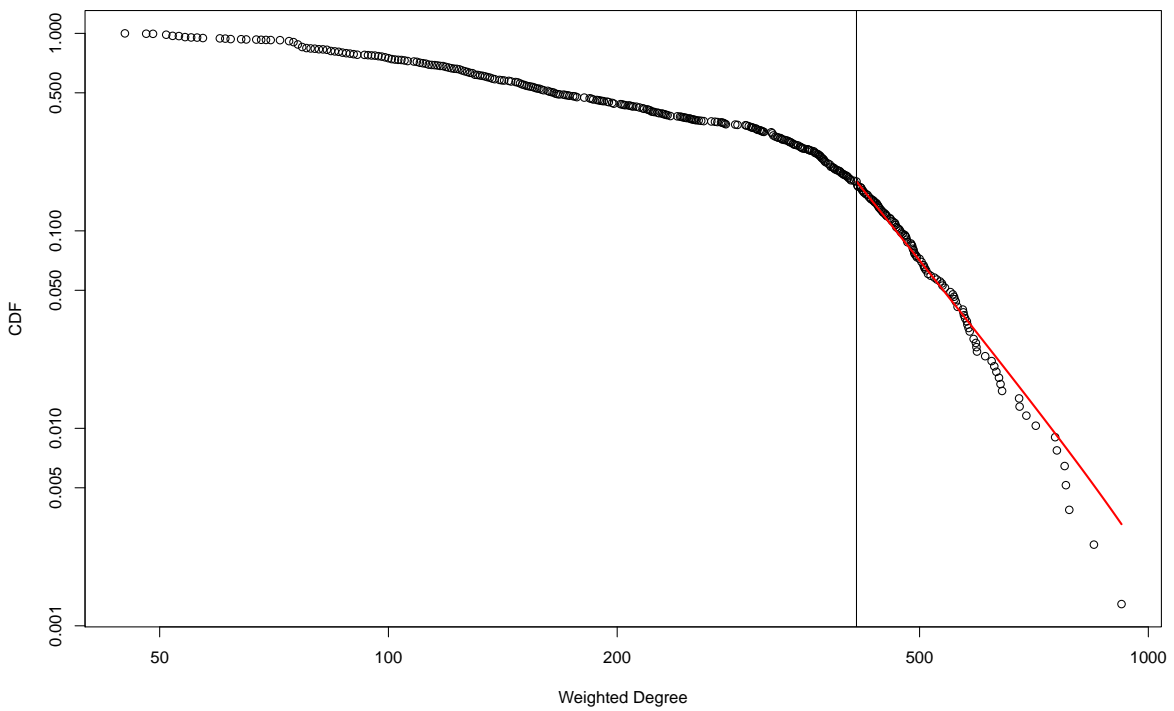

Fig. 4 Cumulative distribution function $P\left(k^{w}\right)$ of the weighted degree $\left(k^{w}\right)$ distribution of the most recent state of the Portuguese governmental network, along with the maximumlikelihood power-law fit line, starting from $k_{m i n}^{w}=413$. The points represent the empirical weighted degree distribution and the line represents the maximum-likelihood estimates of the power-law distribution.

Since the obtained $p$-value is large, we cannot rule out the power-law model because there is enough statistical evidence that the tail of the weighted degree distribution follows a power-law distribution. The line of best fit has the following estimated parameters: $k_{\text {min }}^{w}=413$ and $\alpha=5.79$.

This result indicates that the strength of the connections of a small set of actors (i.e., 132 actors in the tail of the weighted degree distribution, which represent $17 \%$ of the global sample) strongly deviate from the majority. This core set of politicians exert much influence on their personal spheres and, thus, can be considered powerful in this sense. Additionally, we observe that since the 10th government (1985-1987) the $p$-value has been high and the corresponding $\alpha$ very stable (slightly above 5 ). The observed fluctuations in the $p$-value since the 10 th government occur when different political parties (or coalitions) are elected. Nonetheless, these dynamics clash with the evolution of the $p$-value in governments prior to the 

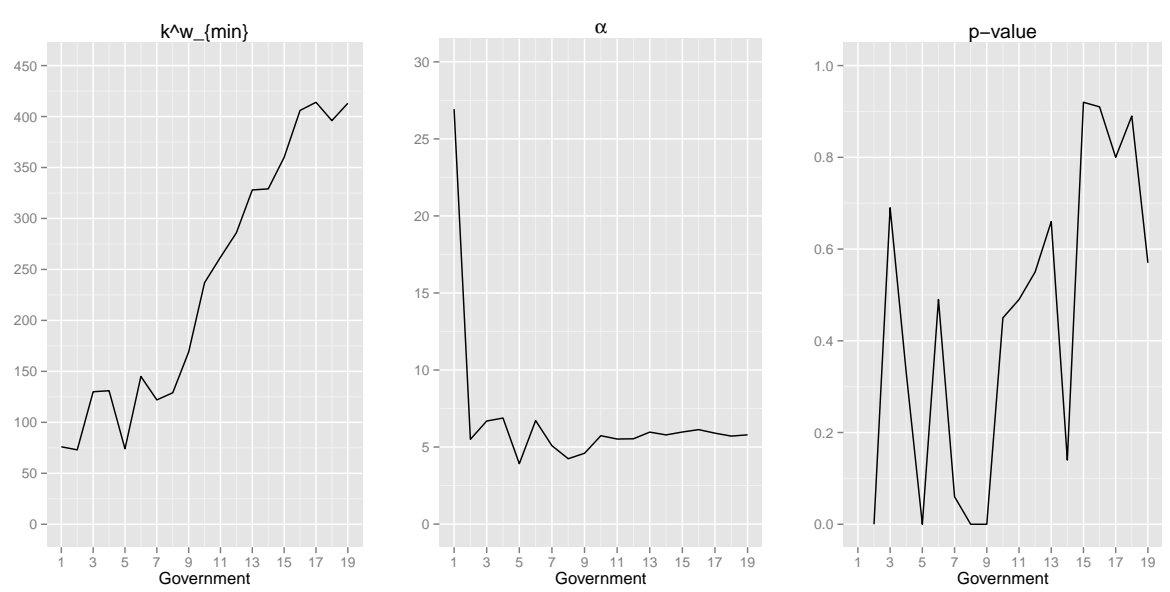

Fig. 5 Evolution of $k_{\text {min }}^{w}, \alpha$ and $p$-value in the 19 Portuguese government networks.

10th government, where the hypothesis of a power-law model is clearly rejected in four occasions (2nd, 5th, 8th and 9th governments).

\subsection{Political Groups}

To analyse the subnetworks associated to each political party, we compute each one of the network measures presented in Section 4.1 for all states of the dynamic network, by political group. This way, we are able to assess the degree of similarity (i) between groups and (ii) between each group and the respective network. Results are presented in Figures 6 and 7. We removed from this analysis four of the previously referenced political groups (AD, Independents, PPM and PRD), due to their residual weight in the global network. As such, our analysis is focused on the political parties PS, PSD and CDS, the ones which are still active.

From the observation of Figure 6 we note that most of the links between members of governments are from actors of either the political party PS or PSD. Also, it is clear again the temporal importance of the 10th government, where we observe that, in both the number of nodes and links, the dispute between these two major groups begins to be constant throughout the remaining governments.

As can be ascertained from Figure 7, approximately $50 \%$ of the total number of links in the global network are endogenous to the membership group. As such, approximately $50 \%$ of the direct connections in the network are established among people pertaining to different political parties. The values of the average degree corroborate this claim for all political parties.

The network centralization index for the subgroups shows that these have evolved with a fair correlation with the global network. Nonetheless, we note that the political group CDS shows a detachment from the other two subgroups mentioned (PS and PSD) for more than 20 years (from the 5th government until the 15th government). After this period, the political party CDS returned to the government, after its last presence in the 8th government (1981-1983). As previously 

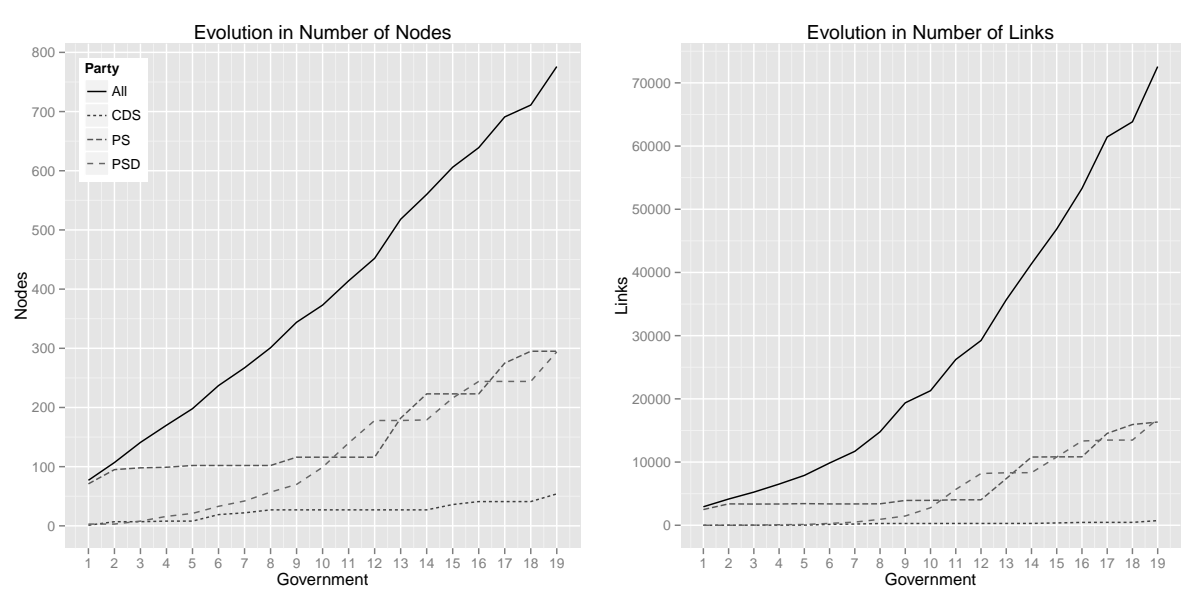

Fig. 6 Evolution in number of nodes and links between nodes throughout the 19 Portuguese government networks by political party.

concluded for the global network, these results suggest the presence of a core set of actors occupying a central position in the structure of these parties.

The evolution of the level of connectivity (as measured by density) within the political parties PS and PSD complies fairly well with the evolution of the global network. As for the political party CDS, results show that for the previously mentioned time period, spanning more than 20 years, the party was extremely connected $(D \approx 0.8)$, proceeding thereafter in a dynamic of approximation to the global network. This is also observed when considering both the clustering coefficient, showing that these subgroups are very tightly-connected with a very high degree of redundant connections amongst them, and the average geodesic distance. Concerning this last metric, we outline two moments (the 5th and the 16th governments) for the subgroup CDS, where the average geodesic distance has a peak, returning then to prior levels.

The fine-grained analysis of the major political parties reveals the strong influence of the political parties PS and PSD on the structural properties of the global network, since these two subgroups show a behavior similar to the one observed for the whole network. This result was expected as these two parties comprise the great majority of nodes and links in the global network and, thus, play a major role in defining its characteristics.

\subsection{Influential Actors}

Finally, we analyse influential actors within the global network. Firstly, we derive the top 10 ranking of actors in the most recent state of the cumulative Portuguese governmental network concerning different centrality measures, in an attempt to capture different dimensions of influence. Secondly, we conduct a resilience analysis, by using a targeted-removal strategy, and evaluate the corresponding effect in the structure of the evolving network. Given previous results and, more specifically, the observation of a high centralization on both the global and subgroup 

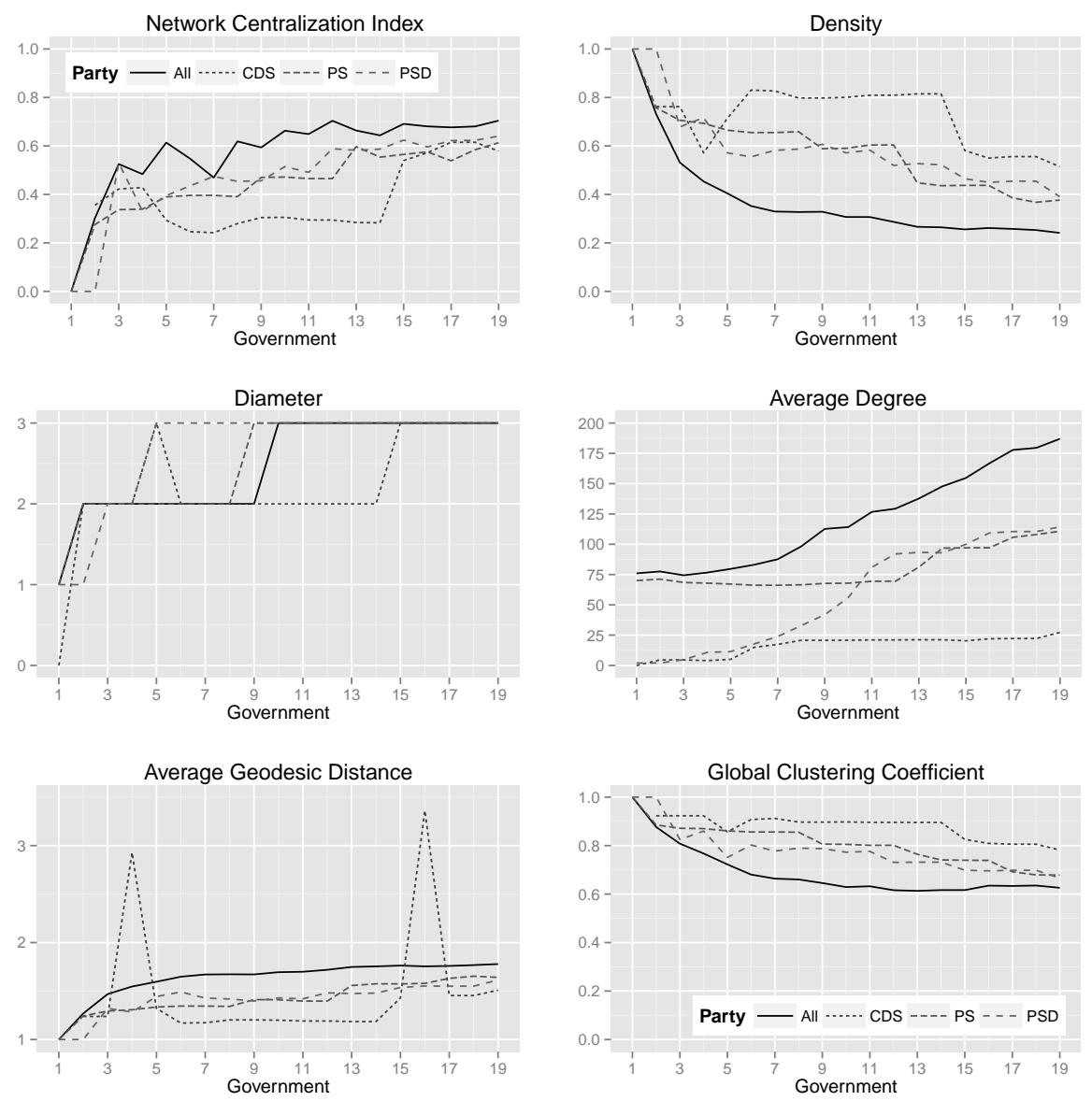

Fig. 7 Evolution of the network centralization index, density, diameter, average degree, average geodesic distance and global clustering coefficient in the 19 states of the evolving Portuguese governmental network, by political party.

networks, it is expected that the most recent state of the network is resilient. However, the conduction of the resilience analysis is generally focused on the objective of understanding and pinpointing the moment when the Portuguese governmental network became resilient and its evolution dynamics.

Table 6 shows the top 10 most central nodes in the most recent state of the Portuguese governmental network according to six node-level measures: degree, weighted degree, weighted eigenvector centrality, weighted betweenness, weighted closeness and power centrality index. By using the power centrality index, we are able to identify the center of power in the network. We implicitly consider that the closer a node is to this center of power, the more influential that node is. 
Table 6 Top 10 ranking of the most central members in the most recent state of the Portuguese governmental network, according to the node-level measures of Section 4.4. Names in bold highlight individuals whose name occurs in three or more rankings, whereas names in italic indicate individuals occurring in exactly two rankings.

\begin{tabular}{|lll|}
\hline Degree & Weighted Degree & Weighted Eigenvector Centrality \\
\hline António de Figueiredo Lopes & António de Figueiredo Lopes & António de Figueiredo Lopes \\
Álvaro Bissaia Barreto & Álvaro Bissaia Barreto & Álvaro Bissaia Barreto \\
Joaquim Ferreira do Amaral & António Bagão Félix & João Salvador Pinheiro \\
João Salvador Pinheiro & João Salvador Pinheiro & António Bagão Félix \\
António Bagão Félix & Joaquim Ferreira do Amaral & Alípio Pereira Dias \\
Fernando Faria de Oliveira & Alípio Pereira Dias & Joaquim Ferreira do Amaral \\
Alípio Pereira Dias & Fernando Faria de Oliveira & Fernando Faria de Oliveira \\
Rui Machete & Rui Machete & Pedro Santana Lopes \\
António Sousa Franco & António Vitorino & António Vitorino \\
José Silva Peneda & Pedro Santana Lopes & Rui Machete \\
\hline \hline Weighted Betweenness & Weighted Closeness & Power Centrality Index \\
\hline António de Figueiredo Lopes & António Sousa Franco & António de Figueiredo Lopes \\
Álvaro Bissaia Barreto & Carlos Correia Gago & Álvaro Bissaia Barreto \\
António Sousa Franco & António Crisóstomo Teixeira & Joaquim Ferreira do Amaral \\
Joaquim Ferreira do Amaral & Joaquim Ferreira do Amaral & Maria Dias Moreira \\
António Correia de Campos & Adalberto Mendo & João Salvador Pinheiro \\
José Silva Peneda & Maria Clara Gomes & Rui Machete \\
Luís Valente de Oliveira & Filipe Lobo Ávila & Mária Bastos Raposo \\
António Bagão Félix & Luís Valente de Oliveira & Fernando Faria de Oliveira \\
Adalberto Mendo & António Pires de Lima & Luís Valente de Oliveira \\
Maria Dias Moreira & José da Silva Lopes & Aníbal Cavaco Silva \\
\hline
\end{tabular}

From the results reported in Table 6 , it is possible to conclude that there is a small group of actors who consistently appear in the top 10 of many of these measures. This elite is unbalanced concerning the political party affiliation. From the 10 unique government members who appear in bold (i.e., who are present in three or more rankings), eight are from PSD, one from PS and one from CDS. All of these actors, except for one single case (António de Figueiredo Lopes), have corporate connections. Concerning the complete list of names (24) of all the top 10 rankings, 14 are from PSD, six from PS, three from CDS and one from PRD. From these 24 actors, 17 are corporate-connected (71\%), whereas seven are not.

After identifying the most influential members of the government in the most recent state of the governmental network, we performed a resilience test aiming to investigate not only the de facto influence that this governmental elite exerts in the general configuration of the networks over time, but also to analyze the temporal dynamics of its emergence. With this purpose, we performed a targeted-removal of several fractions of the most influential actors (namely, 5\%,10\%,15\% and 20\%), as measured by the power centrality index, in all states of the evolving network. The results of the resilience analysis are presented in Figure 8.

From the analysis of Figure 8, we conclude that the network diameter is extremely resilient to the targeted removal of the most influential government members. Since the 10th Government (1985-1987), even when removing an unrealistic $20 \%$ of the most important actors in the network, the diameter remains constant and equal to $D=3$ and the average geodesic distance remains framed within a small interval $(\approx[1.75,2])$.

Although the network is highly centralized with respect to the power centrality index, as can be ascertained from the network centralization value in Figure 2, the results of the structural resilience analysis suggest that the network is strikingly robust to the targeted removal of a meaningful fraction of the most influential nodes (similar results may be found in other situations such as in the work of 

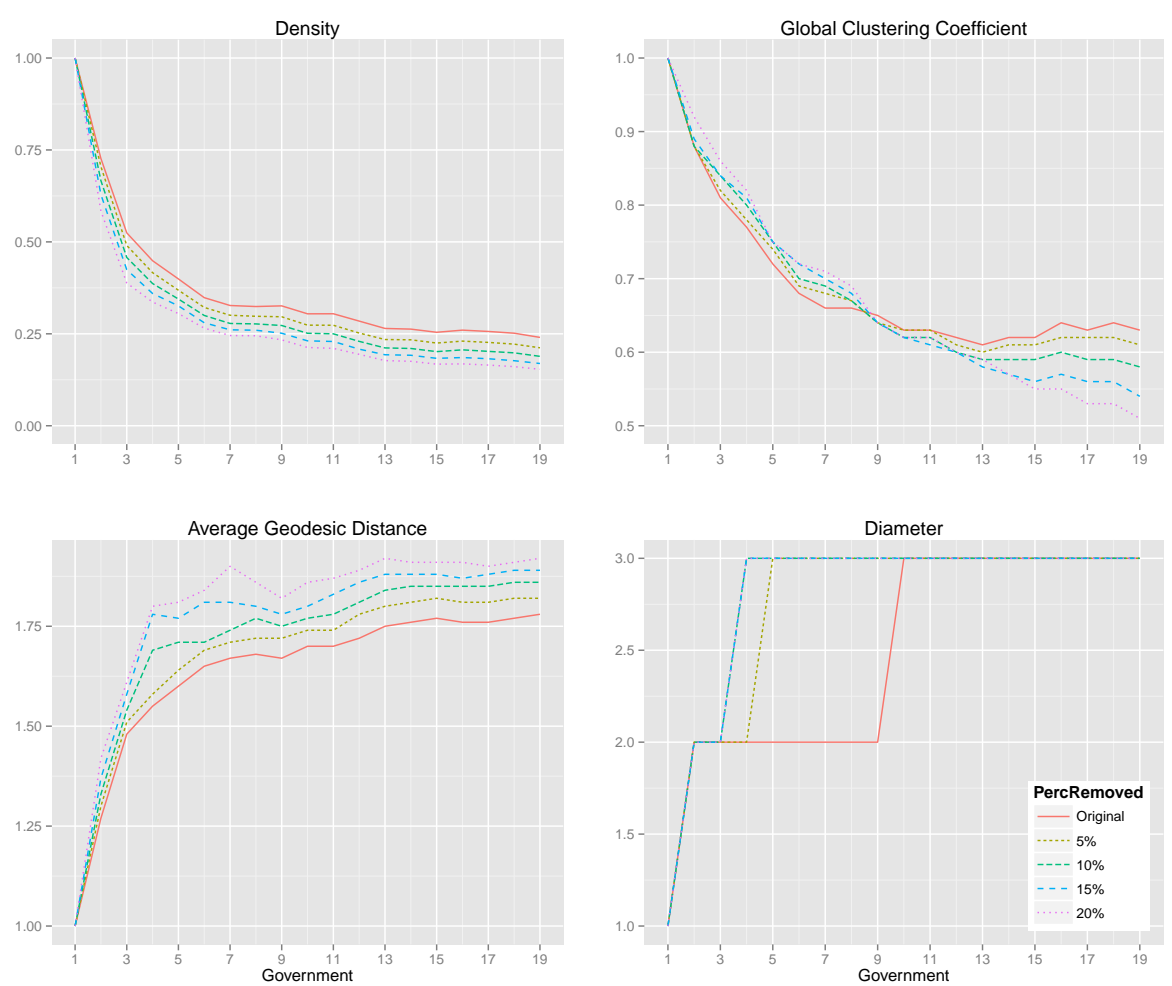

Fig. 8 Impact of the targeted removal of a given fraction of the most influential actors (w.r.t. the Power Centrality Index) on the connectivity and reachability of the Portuguese governmental network. The network connectivity is measured by the density and the weighted clustering coefficient, whereas the reachability in the network is measured by the average geodesic distance and diameter.

Lusseau [31] or Joyce et al. [25]). A possible explanation for this structural robustness is the high neighborhood connectivity among the peripheral nodes in the Portuguese governmental network. Nonetheless, when analyzing its evolution over time, we are able to identify a tipping point in structural robustness. Between governments 9th (1983-1985) and 10th (1985-1987) we observe that the removal of the most influential nodes starts to have an negative effect on the clustering of nodes, since the removal of targeted nodes leads to the disbanding of several cliques. This may translate as a moment in time where the dynamics of the evolving network achieved a point in size and structure where the most influential nodes do in fact play an important role in connectivity. However, as referred to previously, this observed structural change did not affect the reachability in the network.

\section{Discussion}

The political functions of a small population are here used as the instrument to reveal and dissect a social network that constitutes the vertex of the system of power. In this case, we verified that one in five of the members of government 
came or went, or both, from or to financial firms or to the top 20 firms in the Stock Market index, that one in seven came or went, or both, from or to power and oil firms or real estate and construction firms. Most of the members of government were, became or are connected to relevant firms and a "promotion effect" could be detected: after their presence in government, the economic connections increased in most cases.

We also found that this network is based upon connections across the party lines divide. In it, 246 nodes are all connected to each other, forming a complete subgraph in which all links are present. It is a dense network, where each node has on average 187 connections, fairly above the Dunbar's threshold of maximum stable social relationships. Evidence also shows that these connections are, on average, split in terms of internal and external connections as to political groups. It is also a highly centralized network, superior to previous cases identified in the literature. And finally, it is robust, as it is resilient to the removal of the central nodes, meaning that its structure is a social construct that is independent by itself of the most important agents or nodes.

However, the temporal analysis of the dynamic network carried out, using a land mark window model, shows information in the evolution of the network that entails evidence as to the process of its development. The analysis was based on four axis: i) general configuration, ii) distribution of power, iii) political groups and $i v$ ) influental actors. From these results a pattern emerges showing distinct evidence of the importance of the period between the 9th and the 11th Government, including the following:

- The presence of a core set of actors in the network, as suggested by the network centrality index, is steady since approximately the 10th Government, as well as the clustering coefficient and diameter;

- According to the Kolmogorov-Smirnov goodness-of-fit test, we observe that since the 10th government (1985-1987) there is statistical evidence to support the hypothesis of the existence of a power-law distribution in the tail of the weighted degree distribution of the networks.

- Concerning the sub-groups, in both the number of nodes and links, the dispute between the two major political parties begins to be constant between the 10th and 11th Government.

- Concerning the resilience analysis, since the 10th Government, even when removing $20 \%$ of the most important actors in the network, the diameter remains constant and equal to $D=3$ and the average geodesic distance remains framed within a small interval $(\approx[1.75,2])$.

- A tipping point in structural robustness is identified between governments 9th and 10th, where we observe that the removal of the most influential nodes begins to have a negative effect on the clustering of nodes.

To further understand the underlying reasons for the results obtained we must consider the political scenario in each of these governments. The 9th Government was defined as a "central block", composed by members of both the political parties PS and PSD; the first and only occourence of such composition. The 10th Government, was the first time that the political party PSD won the legislative elections by itself; it had been part of previous governments in the coalition AD. The 11th Government was the first time that a political party, PSD, won the elections by majority. 
Overlapping the obtained results and these scenarios, we find that the connections established between these two major political parties in the "central block" government, established a considerable proximity between them. This approximation was aggravated in the two following governments as shown by the SNA metrics used. Overall, results show that this period characterized the overall network until today due to bridging the gap between the two major parties, but also by establishing network-wise the bipartisan political system observed until today.

Finally, intersecting this discussion with the cumulative advantage process and the analysis of the most influent nodes given by Table 6 , we observe that from the 10 individuals whose name occurs in three or more rankings, 9 of those members were part of one of the three mentioned governments (9th, 10th, 11th) ${ }^{4}$.

\section{Conclusions}

The consideration of the whole population of members of all governments established in the constitutional period of the Portuguese democracy (after the vote of the Constitutional Law following the end of the dictatorship), and not a sample of ministers, has no parallel in previous research on social and political networks. The presentation of this global network encompassing almost four decades (1976-2013) and 776 members of government highlights the structure of the political-economic connections as the basis of the edifice of power. Resorting to SNA, we studied the dynamic of the social network of the Portuguese Government in four dimensions: i) general configuration, ii) distribution of power, iii) political groups and iv) influental actors.

Our empirical conclusion is that this network exhibits a global property: its behavior reveals the density of connections and confirm the homogenization process it creates. The network is more than the sum of its smaller parts (e.g., parties in government) and shows stability and robustness. As for the latter, we study the evolution of the robustness of the network, identifying the period in which a set of most influental actors begin to play a role in maintaining the structural properties of the network (between the 9 th and the 11th Government). Furthermore, through a comparative analysis of the major political parties (PS and PSD) we show that PSD has a greater advantage in terms of influence over the global network: the greater majority of the most central nodes in the network belong to this party and corporate- or business-connected.

Other dimensions of the network are to be studied: the political connections to privatizations, to the establishment of public-private partnerships, the role of the large lawyers firms and the inclusion of ex-members of governments, the role of education and the previous choice of professional careers.

Acknowledgements The authors would like to thank the anonymous reviewers, João Teixeira Lopes, Jorge Costa and Adriano Campos for their comments and reviews.

4 The only individual which didn't take part of those governments, was António de Sousa Franco (PS). 


\section{References}

1. Adamic, L.A.: The small world web. In: Research and Advanced Technology for Digital Libraries, pp. 443-452. Springer (1999)

2. Agrawal, A., Knoeber, C.: Do some outside directors play a political role? Journal of Law and Economics 44(1), 179-198 (2001)

3. Barabási, A.L., Bonabeau, E.: Scale-free networks. Scientific American 288, 60-69 (2003)

4. Barrat, A., Barthelemy, M., Pastor-Satorras, R., Vespignani, A.: The architecture of complex weighted networks. Proceedings of the National Academy of Sciences of the United States of America 101(11), 3747-3752 (2004)

5. Bassett, D.S., Bullmore, E.: Small-world brain networks. The Neuroscientist 12(6), 512$523(2006)$

6. Bello, J., Rolfe, M.: Is influence mightier than selection? Forging agreement in political discussion networks during a campaign. Social Networks 36, 134-146 (2014)

7. Bertrand, M., Kramarz, F., Schoar, A.: Politically connected CEOs and corporate outcomes: Evidence from France (2004)

8. Bonacich, P.: Factoring and weighting approaches to status scores and clique identification. Journal of Mathematical Sociology 2(1), 113-120 (1972)

9. Boubakri, N., Cosset, J.C., Saffar, W.: Political connections of newly privatized firms. Journal of Corporate Finance 14(5), 654-673 (2008)

10. Brandes, U.: A faster algorithm for betweenness centrality*. Journal of Mathematical Sociology 25(2), 163-177 (2001)

11. Camp, R.: Politics in Mexico. The democratic consolidation, 5th edn. Oxford University Press (2007)

12. Claessens, S., Feijen, E., Laeven, L.: Political connections and preferential access to finance: The role of campaign contributions. Tech. Rep. 6045, C.E.P.R. Discussion Papers (2007)

13. Clauset, A., Shalizi, C.R., Newman, M.E.J.: Power-law distributions in empirical data SIAM Review 51(4), 661-703 (2009)

14. Costa, J., Fazenda, L., Honório, C., Louçã, F., Rosas, F.: Os Donos de Portugal. Afrontamento (2010)

15. Cull, R., Xu, L.: Institutions, ownership, and finance: The determinants of profit reinvestment among Chinese firms. Journal of Financial Economics 77(1), 117-146 (2005)

16. Davis, G.F., Yoo, M., Baker, W.E.: The small world of the American corporate elite, 1982-2001. Strategic Organization 1(3), 301-326 (2003)

17. Dinc, S.: Politicians and banks: Political influences on government-owned banks in emerging markets. Journal of Financial Economics 77(2), 453-479 (2005)

18. Dunbar, R.I.: Neocortex size as a constraint on group size in primates. Journal of Human Evolution 22(6), 469-493 (1992)

19. Ebel, H., Mielsch, L.I., Bornholdt, S.: Scale-free topology of e-mail networks. Physical Review E 66(3), 035,103 (2002)

20. Erdős, P., Rényi, A.: On the evolution of random graphs. Publications of the Mathematical Institute of the Hungarian Academy of Sciences 5(1960), 17-61 (1960)

21. Faccio, M., Masulis, R.W., McConnell, J.J.: Political connections and corporate bailouts. The Journal of Finance 61(6), 2597-2635 (2006)

22. Freeman, L.C.: Centrality in social networks: Conceptual clarification. Social Networks 1(3), 215-239 (1979)

23. Gil-Mendieta, J., Schmidt, S.: The political network in Mexico. Social Networks 18(4), 355-381 (1996)

24. Heaney, M.T.: Multiplex networks and interest group influence reputation: An exponential random graph model. Social Networks pp. 66-81 (2014)

25. Joyce, K.E., Hayasaka, S., Laurienti, P.J.: The human functional brain network demonstrates structural and dynamical resilience to targeted attack. PLoS Computational Biology 9(1), e1002,885 (2013)

26. Khwaja, A.I., Mian, A.: Do lenders favor politically connected firms? Rent provision in an emerging financial market. The Quarterly Journal of Economics 120(4), 1371-1411 (2005)

27. Li, H., Meng, L., Wang, Q., Zhou, L.A.: Political connections, financing and firm performance: Evidence from Chinese private firms. Journal of Development Economics 87(2), 283-299 (2008)

28. Li, W., Cai, X.: Empirical analysis of a scale-free railway network in China. Physica A: Statistical Mechanics and its Applications 382(2), 693-703 (2007) 
29. Li, X., Jin, Y.Y., Chen, G.: Complexity and synchronization of the World trade web. Physica A: Statistical Mechanics and its Applications 328(1), 287-296 (2003)

30. Louçã, F., Lopes, J.T., Costa, J.: Os Burgueses. Bertrand (2014)

31. Lusseau, D.: The emergent properties of a dolphin social network. Proceedings of the Royal Society of London B: Biological Sciences 270(Suppl 2), S186-S188 (2003)

32. McClurg, S.D., Young, J.K.: Political networks. PS: Political Science \& Politics 44(1), 39-43 (2011)

33. Bandeira-de Mello, R., Marcon, R.: The value of business group affiliation for political connections: preferential lending in Brazil. In: AOM (ed.) Annual Meeting of the Academy of Management, vol. 2 (2011)

34. Mendieta, J.G., Schmidt, S., Castro, J., Ruiz, A.: A dynamic analysis of the Mexican power network. Connections 20(2), 34-55 (1997)

35. Mokken, R.J., Stokman, F.N.: Corporate-governmental networks in the Netherlands. Social Networks 1(4), 333 - 358 (1978-1979)

36. Moniz, N., Campos, A.: Relational data on members of portuguese governments (1976-2014). Data 1(1), 1 (2015). DOI 10.3390/data1010001. URL http://www.mdpi.com/2306-5729/1/1/1

37. Montoya, J.M., Solé, R.V.: Small world patterns in food webs. Journal of Theoretical Biology 214(3), 405-412 (2002)

38. Newman, M.E.: Scientific collaboration networks II. shortest paths, weighted networks, and centrality. Physical Review E 64(1), 016,132 (2001)

39. Newman, M.E.: The structure of scientific collaboration networks. Proceedings of the National Academy of Sciences 98(2), 404-409 (2001)

40. Newman, M.E.: Analysis of weighted networks. Physical Review E 70(5), 056,131 (2004)

41. Newman, M.E.: Power laws, Pareto distributions and Zipf's law. Contemporary Physics 46(5), 323-351 (2005)

42. Niessen, A., Ruenzi, S.: Political connectedness and firm performance: Evidence from Germany. CFR Working Papers 07-15, University of Cologne, Centre for Financial Research (CFR) (2009)

43. Opsahl, T., Agneessens, F., Skvoretz, J.: Node centrality in weighted networks: Generalizing degree and shortest paths. Social Networks 32(3), 245-251 (2010)

44. Parigi, P., Sartori, L.: The political party as a network of cleavages: Disclosing the inner structure of italian political parties in the seventies. Social Networks 36, 54-65 (2014)

45. Price, D.D.S.: A general theory of bibliometric and other cumulative advantage processes. Journal of the American Society for Information Science 27(5), 292-306 (1976)

46. Ribeiro, J., Fernandes, L., Ramos, M.: Grande indústria, banca e grupos financeiros (195373). Análise Social 23(99), 745-1018 (1987)

47. Siegel, D.A.: Social networks in comparative perspective. PS: Political Science \& Politics 44(1), 51-54 (2011)

48. Sinclair, P.A.: A representation for the Mexican political networks. Social Networks 29(1), 81-92 (2007)

49. Sinclair, P.A.: The political networks of Mexico and measuring centralization. ProcediaSocial and Behavioral Sciences 10, 26-35 (2011)

50. Szwarcberg, M.: Revisiting clientelism: A network analysis of problem-solving networks in Argentina. Social Networks 34(2), 230-240 (2012)

51. Walsh, T.: Search in a small world. In: IJCAI, vol. 99, pp. 1172-1177 (1999)

52. Watts, D.J.: Networks, dynamics, and the small-world phenomenon 1. American Journal of Sociology 105(2), 493-527 (1999)

53. Watts, D.J., Strogatz, S.H.: Collective dynamics of small-world networks. Nature 393(6684), 440-442 (1998) 